\title{
A Teoria Gerativa nos estudos de aquisição do português brasileiro
}

\author{
Maria Cecília Perroni \\ Unicamp
}

\section{Abstract}

The aim of this paper is to present some of the studies on the acquisition of Brazilian Portuguese as a first language, which have been published in the last few years in our country, making use of the generative grammar theory in their analysis of the child's speech data. The topics that have been analysed are the systems: D, IP, CP, and complementation/adjunction in complex sentences. Additional research on the acquisition of Brazilian Portuguese as a second language is also shown. The studies briefly discussed here can contribute to prove the relevance of the generative theory in the development of the Language Acquisition area. 


\section{INTRODUÇÃO}

questão da aquisição da linguagem pela criança pequena 1 tem sido uma das mais importantes para a teoria lingüística 1 em geral, ocupando um lugar de destaque na teoria da sintaxe gerativa, desde o modelo "standard" (CHOMSKY, 1965) e chegando na década de oitenta a consistir em uma das perguntas básicas de sua versão conhecida como de "Princípios e Parâmetros" (CHOMSKY, 1981, 1986), assim como no atual "Programa Minimalista" (CHOMSKY, 1995).

Se, por um lado, o interesse pela aquisição sempre existiu, por outro, convém lembrar que antes da versão de Princípios e Parâmetros a teoria gerativa não atraía muito os pesquisadores da área de aquisição da linguagem, devido à própria instabilidade interna da teoria, uma vez que a profusão de regras e transformações, revistas constantemente, chegou a produzir um recuo das investigações com dados empíricos.

Com efeito, é apenas com a divulgação da versão de Princípios e Parâmetros que os pesquisadores da área se sentiram mais à vontade para voltar à teoria gerativa e dedicar esforços no sentido de responder aos problemas de aquisição. Como mostram KATO (1995b, 1999) e GALVES (1995), as novas versões da teoria permitem agora tratar dados empíricos da aquisição da língua materna pela criança pequena.

O chamado "problema lógico da aquisição" é ali tratado através da idealização de um processo instantâneo, enquanto que o psicológico, da aquisição em tempo real, tem levantado as questões de como, por exemplo, são ativados os princípios da Gramática Universal -GU-, como os parâmetros são fixados e qual é a natureza do conhecimento da criança nas diversas etapas do desenvolvimento. As simplificações feitas nas versões mais recentes da teoria reduzem a tarefa da aquisição à aprendizagem do léxico da língua alvo, a variação 
paramétrica se localizando basicamente nas chamadas categorias funcionais (CHOMSKY, 1995).

Uma resenha bastante abrangente dos estudos teóricos gerativistas já feitos no Brasil pode ser encontrada em KATO \& RAMOS (1999), no número especial da revista DELTA - Trinta anos de Abralin.

Adicionalmente, nosso objetivo aqui é apresentar brevemente uma retomada de alguns dos estudos de Aquisição do Português Brasileiro ${ }^{1}$ que têm se baseado em tal teoria, o que será feito na seção 2. Esta deverá ser, obviamente, uma resenha apenas parcial, tanto por limitações de nossa informação sobre trabalhos ainda em andamento em outros centros de pesquisa, como porque sabemos que estes crescem a cada dia. Limitar-nos-emos, assim, a elencar alguns daqueles trabalhos que tratam do desenvolvimento de diversos aspectos da sintaxe do $\mathrm{PB}$ em alguns meios acadêmicos brasileiros. Motivados pelo potencial explicativo que as simplificações na teoria gerativa trouxeram, os estudos revistos na seção 2 começaram a surgir no nosso meio já na década de noventa. Aqueles que são aqui comentados podem ilustrar tanto o interesse quanto o alcance das novas versões da teoria.

Na seção 3, resumiremos alguns dos resultados de nossa pesquisa realizada nos últimos anos sobre a aquisição do PB por duas crianças sujeito (um menino e uma menina), na interface sintaxe/semântica, quando foram analisados os processos de complementação e de adjunção em sentenças complexas entre os 2;0 e os 5;0 de idade. Nossos dados têm origem no antigo projeto de Aquisição da Linguagem do DL, IEL, Unicamp, hoje parte do banco de dados do CEDAE/IEL. ${ }^{2}$

\section{BREVE LEVANTAMENTO DOS ESTUDOS GERATIVISTAS DE AQUISIÇÃO DO PB}

Grande parte dos estudos gerativistas da Aquisição do PB no Brasil defende a sua versão continuísta, que propõe que a gramática da criança é semelhante à do adulto, com todos os princípios já ativados desde o início, conforme já proposto por autores como HYAMS (1986, 1994) e PINKER (1984) para o inglês, e por KATO 
(1995a) para o português. Tais estudos enfatizam a presença de categorias funcionais desde muito cedo na gramática das crianças, em oposição a hipóteses maturacionistas, como a defendida por RADFORD (1990). Como se sabe, este autor propõe que a criança pequena primeiro adquire e projeta somente as categorias lexicais $(\mathrm{N}, \mathrm{V}, \mathrm{A}$ e P), para só mais tarde adquirir as funcionais. De fato o autor é já extensamente citado nos debates entre teorias continuístas e teorias maturacionais do desenvolvimento como um dos pioneiros da hipótese maturacional na Aquisição da Linguagem.

A grande questão a ser explicada é então: por que os enunciados das crianças pequenas, em fases iniciais do desenvolvimento, são muitas vezes truncados, parecendo demonstrar a ausência de algumas categorias?

A explicação oferecida pelos autores adeptos do continuísmo é a de que tal fato se deve a desconhecimento, pela criança, dos itens lexicais particulares da língua alvo, sendo compatível com a versão mais recente da teoria gerativa, que vê a tarefa de aquisição como uma questão de aquisição do léxico e morfologia da língua materna. Não haveria, assim, uma precedência consistente de categorias lexicais sobre funcionais durante o processo de aquisição.

Os estudos aqui revistos têm testado as duas hipóteses, com base em dados de aquisição do PB, em sua maior parte dados longitudinais, observacionais, provenientes tanto do Banco de Dados acima citado, como de outras fontes, conforme se verá a seguir.

Começando com IP, temos o trabalho de OLIVEIRA (2000), que analisou o uso dos verbos ser e estar em posição de cópula e dos auxiliares não modais (estar/ir) em dados de nove crianças entre os 20 e os 34 meses de idade, falantes de um dialeto baiano, encontrando evidências (baseadas nos critérios de produtividade, c-seleção e propriedade) de que as crianças sujeito já demonstravam ter adquirido $I P$, já que faziam distinções sintático/semânticas entre aqueles verbos.

Com relação ao sistema $C$, cite-se a pesquisa de SIKANSI (1999) sobre a emergência das perguntas e outras estruturas com elementos 
Qu- desde os 2;0 de idade até os 3;10, baseada nos dados de uma outra criança paulista. Entre seus resultados destacamos que até os 2;6 as interrogativas encontradas foram aquelas com a expressão cadê, seguida de SN. A partir dessa etapa, outras estruturas interrogativas com Qu- começam a emergir, embora o sistema adulto ainda não tivesse se completado na época do final de seus dados. Sua análise evidencia a alta incidência de estruturas com $Q u$ deslocado à esquerda e não "in situ", o mesmo confirmando o estudo posterior de GROLLA (2000).

Em seu trabalho, GROLLA (2000) explora as construções de topicalização, presentes na chamada "periferia esquerda da sentença", fazendo uso da tese do CP expandido, de RIZZI (1995), desde os 2;0 de idade (e até os 4;0), nos dados de uma criança do projeto da Unicamp. A autora constata que toda essa aquisição é relativamente lenta, as perguntas com Qu- surgindo já aos 2;0, seguidas das contruções de clivagem e das relativas, que se estabilizam perto dos 3;0. Os progressos obtidos até os 4;0 mostram que a criança nessa idade já se aproxima bastante da gramática do PB do adulto, ativando mais de uma projeção funcional do sistema $C$ simultaneamente e completando sua aquisição de todos os elementos Qu-do PB.

Se pensarmos também no sistema $D$, vemos que PALMIERE (1997) atesta sua presença nos dados de uma criança sujeito do projeto campineiro já aos 1;7, questionando a proposta de RADFORD (1990) de que nos períodos iniciais da aquisição categorias funcionais não estariam presentes.

Os dados da mesma criança foram analisados por CERQUEIRA (1996, 1999), que pesquisou longitudinalmente sua aquisição dos possessivos desde os 1;8 de idade. O autor observou a aquisição dos elementos meu e seu entre os 1;8 e os 1;10, mostrando que desde essa idade a criança tem conhecimento da indicação de posse desses constituintes. $\mathrm{O}$ autor os encontra inicialmente em posição posterior ao substantivo e em seguida precedendo-o, o que demonstra uma mudança na gramática da criança. Sua análise do sintagma nominal se baseou em pesquisas gerativistas em que são discutidas a posição 
do determinante e a do possessivo. Conclui então que aos 1;10 a gramática da criança já dipõe da categoria funcional $D$, o que favorece a adoção de uma teoria aquisicionista da competência plena.

Com relação à fixação de parâmetros, lembremos da importante contribuição de SIMÕES (1997, 1999) sobre o parâmetro do sujeito nulo, com dados de uma criança gaúcha, dos 2;4 aos 4;0 de idade, trabalho que mostra o uso produtivo do sujeito nulo pela criança, em resultados bastante semelhantes aos dos adultos (de estudos comparados por ela), não havendo desvios em relação ao input.

O mesmo parâmetro foi analisado por OLIVEIRA (1999), que o testou com dados de uma criança do projeto campineiro, chegando a resultados significativos que comprovam a mudança em curso da língua alvo, marcada positivamente quanto ao parâmetro em questão, e caminhando em direção a uma marcação negativa. Esta autora também compara seus resultados das crianças brasileiras com os de outro estudo seu, sobre a aquisição do mesmo parâmetro no italiano, uma língua marcada positivamente quanto ao parâmetro em questão. Fortalecendo a importância dada no inatismo ao papel do input na marcação do parâmetro pelas crianças, a autora identifica a natureza dos dados simples e robustos nas duas línguas examinadas, os quais seriam responsáveis pela fixação do parâmetro.

Parte dos dados campineiros são revistos no estudo de KATO (1994) sobre o objeto nulo na mesma criança, defendendo a autora uma versão continuista da Aquisição da linguagem. Uma estrutura plena para os enunciados das crianças é também proposta por KATO (1995b) em sua análise de uma fase precoce de construções nãofinitas do PB, comparando-os com dados de outros estudos já realizados em outras línguas, como o inglês.

Em pesquisa anterior (PERRONI, 1999), discutimos as estruturas com para, nos dados das mesmas crianças sujeito aqui tratados, na mesma faixa etária, com ênfase na questão da categorização do item: se preposição lexical, ou funcional, chegando à conclusão de que se trata de uma categoria híbrida, e fazendo uso do questionamento já lançado por HAUMANN (1997) sobre a distinção rígida demais proposta pela teoria gerativa, de dois tipos de categorias. 
Os mesmos dados das mesmas crianças foram analisados por nós em pesquisa posterior (PERRONI, 2001) no que se refere à aquisição das orações relativas e das clivadas, quando tentamos mostrar as suas inter-relações e discutir o fenômeno da dificuldade, apontada já por diversos autores, que algumas relativas apresentam a crianças pequenas em tarefas de compreensão.

Além dessas pesquisas com crianças pequenas, o trabalho de CORREA (1998) sobre a aquisição das orações relativas com dados tanto do Português falado, como escrito no Brasil (crianças e jovens falantes de um dialeto paulista), também faz uso da teoria gerativa, na versão de Princípios e Parâmetros, para explicar o fenômeno do predomínio da relativa não-padrão até a idade adulta de sujeitos, mesmo aqueles com alto índice de escolaridade.

A teoria de princípios e parâmetros foi também utilizada em pesquisas sobre a aquisição do português como segunda língua: salientemos o trabalho de GONÇALVES (1997) sobre o parâmetro do posicionamento do núcleo (linearidade), com dados de crianças falantes do japonês como língua materna. Tais crianças são brasileiras, nascidas e criadas num ambiente sui generis: o de uma pequena comunidade japonesa no interior do estado de São Paulo, onde se fala o japonês, senda esta, portanto, sua língua materna. O Português só vai ser adquirido por aquelas crianças à época do ingresso na escola, aos sete anos de idade. O autor mostrou o papel da L1 (uma língua "head last") na aquisição da L2 (uma língua "head first"), propondo que de fato existe transferência ("transfer") e evidências de remarcação de parâmetro, uma questão ainda bastante debatida na área.

Em seguida, salientemos a pesquisa de XAVIER (1999), que se baseou nos dados de um jovem falante do chinês como língua materna, adquirindo o PB (dialeto baiano, de Salvador) como L2, também com relação ao parâmetro do sujeito nulo. Em seu estudo, Xavier levanta a questão da possibilidade ou não de acesso à GU por falantes já adultos (após o período crítico da Aquisição da Linguagem). Seria a GU ainda acessível, uma vez que uma determinada língua já foi adquirida? Seus resultados não puderam solucionar a questão 
(haveria remarcação de parâmetros?), porque o objeto de estudo examinado pela autora correspondia no chinês (L1 do sujeito) ao valor "default" do mesmo na GU. Levanta assim a questão, ainda não resolvida, de possibilidade de acesso à GU na aquisição de L2.

Em FONSECA (1999), a aquisição da concordância negativa (CN) do português como segunda língua foi estudada com base em dados de um adulto falante do alemão como língua materna, durante as etapas iniciais de sua aquisição, quando de sua chegada ao Brasil (Salvador, Bahia). A autora analisa o fenômeno, comum nas línguas românicas, mas ausente no alemão, da presença de dois ou mais elementos negativos em uma mesma sentença, com interpretação de uma negativa simples (Ex.: "Eu não acho nada".). Testando a hipótese da possibilidade da GU ainda atuar na aquisição de segunda língua, em oposição a outra hipótese alternativa, a autora analisa seus resultados com base no caminho percorrido pelo falante do alemão nessa aquisição. Constata que foi necessário, em primeiro lugar, a aquisição da negação simples com as palavras $n$ (como nada, ninguém, nenhum), e que o fenômeno da CN só surge na fala do sujeito depois de dois meses de imersão total à L2, consolidando-se três meses depois. Como se tratou de um espaço de tempo relativamente pequeno, a autora concluiu que a GU provavelmente teve um papel nessa aquisição, confirmando a hipótese originalmente levantada.

Há ainda outras pesquisas em andamento, o campo é fértil e promete grandes progressos, num prazo não muito longo, mostrando agora que a Aquisição da Linguagem não pode mais ser vista como uma área que se contenta com a aplicação ou testagem de teorias lingüísticas vigentes, mas que pode, como é desejável, contribuir efetivamente para o próprio desenvolvimento das teorias, como idealizado por Chomsky em inúmeras ocasiões.

De fato, esses resultados começam a alimentar a própria teoria, lançando as primeiras luzes sobre questões tão importantes como a da marcação de determinados parâmetros, ${ }^{3}$ seu valor "default" na GU, a possibilidade de haver remarcação, no caso da aquisição de duas línguas, a possibilidade de haver uma marcação ambígua (marcação 
ao mesmo tempo positiva e negativa), no caso de línguas em evidente processo de mudança, como é o caso do $\mathrm{PB}$, a discussão da natureza dos chamados traços fortes, e seu papel no movimento (cf. CHOMSKY, 1995).

A maior parte desses estudos aqui mencionados comprova as teorias continuístas da Aquisição. De fato, como salienta KATO (1999), se não há sistema D, não há referência, sem o sistema I os enunciados não poderiam ser nem verdadeiros nem falsos, sem C não poderiam ser interpretados nem como asserções, nem ou perguntas. Somando-se tudo isso, o resultado obrigatoriamente significaria que a sintaxe da criança não teria Forma Lógica, o que sem dúvida seria um absurdo.

Ora, desde o trabalho pioneiro de BROWN (1973), já é consensual na área que os primeiros enunciados das crianças são usados para fazer "referência" a entidades, principalmente a objetos presentes no momento da conversação, predicando algo sobre elas (declarando afirmativa ou negativamente), ou atuam tais enunciados como "perguntas" sobre estados de coisas observáveis, ou como "pedidos" para que o adulto faça algo, geralmente em seu favor. Se isto se dá, então as gramáticas iniciais das crianças já devem dispor de posições estruturais destinadas a alojar os constituintes responsáveis por, por exemplo, força ilocucionária e finitude, estabelecendo a interface do sintático com o semântico e o discursivo. Dessa forma, a discussão em andamento na área de Aquisição da Linguagem pode colaborar para um melhor entendimento da própria natureza da GU.

\section{COMPLEMENTAÇÃO E ADJUNÇÃO EM SENTENÇAS COMPLEXAS NA AQUISIÇÃO DO PB}

Nossa análise dos dados longitudinais de duas crianças sujeito do projeto da Unicamp, um menino e uma menina, ${ }^{4}$ entre os $2 ; 0$ e os 5;0 de idade, foi realizada com o objetivo inicial de detectar as primeiras manifestações de sentenças complexas na fala da criança e analisá-las dentro de uma perspectiva gerativista. 
As questões então exploradas dizem respeito à identificação das estruturas infantis tanto de complementação, como de adjunção e às suas inter-relações com algumas categorias funcionais, como COMP.

Como apontam KATO e MIOTO (inéd.), há dois aspectos principais a considerar quando se trata de subordinação de sentenças: o interno, que diz respeito à própria estrutura da sentença, e o externo, que diz respeito à identificação da natureza e posição na configuração dos constituintes responsáveis pelo licenciamento e pela estrutura da sentença subordinada. Basicamente, estas têm que ser licenciadas por um núcleo externo, sob regência, ou adjuntas a um constituinte não-nuclear externo. Então os processos de subordinação são dois: um que surbordina um CP como argumento de um núcleo e um que adjunge um CP a uma projeção máxima. No nosso caso, o aspecto externo foi priorizado, já que se buscava analisar a relação das orações encaixadas com a sentença matriz, como e quando eram licenciadas na gramática da criança.

Ao tratar das sentenças complexas, analisamos COMP, uma categoria funcional, a princípio comparando dois pontos de vista alternativos: seria ou não a gramática da criança diferente da do adulto? Como mencionado na seção anterior, RADFORD (1990), MEISEL \& MÜLLER (1992) e MEISEL (1994) são da opinião que tal gramática difere de modo significativo da do adulto. As primeiras sentenças infantis seriam basicamente VPs, antes da emergência das categorias funcionais. Assim, CP seria adquirido só mais tarde, depois de IP.

MEISEL \& MÜLLER (1992), baseados em seu conhecido estudo sobre três crianças adquirindo o alemão e o francês simultaneamente, com dados que cobrem o período dos 1;5 até os 5;0 e 5;11, afirmam que Inf/Agr. está presente desde muito cedo, mas que COMP e suas projeções não estão.

Os principais argumentos apresentados por aqueles autores são os seguintes. O primeiro é que as crianças sujeito não fariam uso de complementadores, começando com alguns do francês apenas em torno dos 2;6-2;11, e mesmo só aos 5;1, no caso do alemão. O segundo é que durante o mesmo período algumas das crianças são capazes 
de usar construções complexas que logicamente são subordinações, mas não exibem o mecanismo sintático de subordinação. O terceiro é que as crianças usam conjunções coordenativas (do tipo de $e$ do português), o que significa que são capazes de processar orações coordenadas. O quarto argumento é que as crianças usam advérbios e preposições que expressam relações semânticas semelhantes à do complementador (correspondentes a por/para, depois, com, porque do português), cujas propriedades formais são partilhadas pelos complementadores, ou seja, são invariantes morfologicamente. Outras propriedades sintáticas relacionadas que estariam também ausentes seriam: elementos à esquerda que são movidos a COMP ou a Spec, CP. na gramática do adulto. MEISEL \& MÜLLER (1992) afirmam que nos dados do francês das suas crianças sujeito não há construções que dependem da existência do sistema $\mathrm{C}$, ou seja, inversão nas interrogativas raízes. Tal desenvolvimento, direcionado lexicalmente, seria retardado nos dados pelo fato de que não haveria na gramática da criança uma posição estrutural disponível para esses itens lexicais.

Que a gramática dessas crianças bilíngües difere da do adulto é também afirmado por MÜLLER (1994), que, entretanto, enfatiza que os resultados das pesquisas até então eram contraditórios. Após mencionar alguns estudos que propõem que CP está disponível só depois de IP, a autora é de opinião que as construções V2 e as interrogativas raízes em línguas V2 estão representadas como Ips. Em sua análise, como na de MEISEL (1994), Inf. já está presente desde muito cedo nas gramáticas das crianças, enquanto COMP não está. Na análise de seus dados, verifica MÜLLER (1994) que as crianças começam a produzir orações encaixadas subordinadas introduzidas por complementadores aos 2;6 uma delas, e aos 2;11 a outra, enquanto a terceira, só aos 3;1. Conclui assim que uma nova posição sintática COMP está presente na gramática francesa daquelas três crianças a partir daquele momento.

Como se sabe, um outro ponto de vista, alternativo à hipótese citada, é defendido por HYAMS (1986 e 1994), a chamada "Full Clause Hypothesis", segundo a qual a criança já começa com projeções máximas IP e CP aos 2;0 de idade. A autora afirma que COMP está disponível 
como um local de pouso para a subida de $\mathrm{V}$ na gramática inicial e, usando de argumentos baseados em línguas V2 e na propriedade do sujeito nulo, argumenta que a gramática da criança projeta CP.

Também na obra de LUST (1994), a maior parte dos artigos advogam uma hipótese continuísta forte, as mudanças, ou variações observadas não sendo vistas como tendo origem em princípios ou parâmetros da GU. Mas, ressaltam os pesquisadores, esta hipótese não significa que o pesquisador seja cego às mudanças de fato ocorridas na linha temporal da aquisição da linguagem pela criança. Pelo contrário, o fato de que a gramática da criança é cada vez mais próxima da do adulto só significa que a GU está sempre presente, dirigindo e restringindo o curso da aquisição.

A fixação dos parâmetros determina não a ordem no tempo da aquisição, mas a sua forma. Há mudanças reais na aquisição e esta envolve conhecimento adquirido de gramáticas de línguas específicas e o necessário mapeamento dos princípios da GU a tais línguas específicas, sendo a hipótese da continuidade uma versão da Hipótese de Projeção Funcional. Ou seja, as projeções frasais (de núcleos funcionais), dadas pela GU, estariam continuamente disponíveis durante o curso da aquisição da linguagem.

LUST (1994) é de opinião que a gramática da criança não é descontínua em relação à do adulto, por uma alegada ausência de categorias funcionais no início do desenvolvimento, como postula RADFORD (1990). Para Lust, a categoria Co está sempre disponível durante o curso da aquisição. Mais ainda: ela não só está disponível, mas tem um papel crucial no processo de aquisição, estando subjacente à marcação de parâmetros muito cedo. Tal debate na área foi inevitável diante da dificuldade de explicar o problema de como categorias funcionais estariam ausentes num período em que as crianças têm operações sintáticas que requerem tais categorias.

HYAMS (1994) defende uma saída para esse dilema, questionando a premissa de que elemento ausente na língua E é igual a categoria ausente na língua I (cf. conceitos de CHOMSKY, 1986, 1995). Segundo a autora, é preciso distinguir entre a aquisição da complementação 
como um fenômeno sintático/semântico, da aquisição dos complementadores, o que é um tipo de aprendizado lexical. Em seu trabalho de 1994, retoma a proposta de um "Princípio de Realização Estrutural", que permite à criança projetar um complemento CP baseada em seu conhecimento semântico do verbo, ie., o conhecimento de que ele seleciona um argumento proposicional. Tal princípio prevê que: "Para que um constituinte seja interpretado como proposicional, deve ser sintaticamente realizado como CP" (HYAMS, 1994, p. 45).

Segundo a mesma autora, o conhecimento desse princípio de complementação é independente da seleção do tempo do complemento de verbos particulares e da escolha do complementador. Seguese daí que os dois devem se desenvolver separadamente, como se espera de um sistema modular, tal qual proposto pela teoria. Sendo assim, a criança pode ter conhecimento da estrutura CP de complementos, enquanto ainda não produz complementadores lexicais.

Passando a nosso estudo com dados do $\mathrm{PB}$, conforme pudemos atestar (PERRONI, 1997), é realmente somente aos 2;6 que surgem os casos de complementação com sentenças complexas, quase todos com que, invariavelmente de acordo com o sistema do PB adulto. Quanto ao se como complementador, é significativamente mais tardio que o que, surgindo pela primeira vez só aos 3;6, com apenas algumas ocorrências esporádicas até os 4;0. A maioria delas surge complementando o verbo ver, para somente depois dos 4;0 surgir com outros verbos.

A idade de manifestação dos complementadores em PB coincide com a idade mencionada nos estudos de MEISEL (1994), MEISEL \& MÜLLER (1992) para o caso do francês (mas não do alemão), assim como para o inglês, conforme atestam BLOOM et al. (1980). Assim, por um lado, este resultado poderia confirmar a hipótese maturacional, se se considerar a existência de COMP na gramática da criança apenas a partir da manifestação do item lexical adequado na língua alvo. Entretanto, ter-se-ia que ignorar a existência precoce das interrogativas (SIKANSI, 1999; KATO, 1999; GROLLA, 2000) e a posição estrutural disponível para a força ilocucional da sentença, presente desde o início. 
Por outro lado, a manifestação de COMP em sentenças complexas pode ser vista como uma questão psicolingüística, que diz respeito à capacidade de processamento lingüístico (no caso, produção) de sentenças complexas, com complementação ou adjunção. A relativa demora de manifestação do complementador teria origem nesse fato, o que estaria de acordo com a afirmação de HYAMS (1994) de que ausência na língua E não significa ausência na língua I.

Fortalecendo esse ponto de vista, uma descoberta curiosa nos nossos dados longitudinais foi a constatação de uma fase do desenvolvimento em que ambas as crianças passam a produzir "duas" sentenças, em vez de apenas "uma", em torno dos 2;6. Ora, como é já classicamente constatado na literatura da área, a fase de duas palavras ("fala telegráfica") segue aquela inicial de apenas uma (cf. BROWN, 1973, e tantos outros autores). No nível da sentença a história se repete. Até os 3;1 de uma das crianças sujeito e os 4;0 da outra, não são encontradas sentenças complexas com mais de duas orações, um provável reflexo da expansão da capacidade de processamento de "uma" unidade para "duas", desta vez no nível da sentença.

As primeiras sentenças encaixadas a uma matriz a se manifestarem nos dados, a partir dos 2;6, são as completivas com que, além de clivadas e relativas, descritas em PERRONI (2000). Alguns exemplos de nossos dados podem ilustrar:

(1.) Eu acho que você tomou de mim o pente. (N. 2;7)

(2.) Pensei que tinha acabado. (N. 3;3)

Como se vê, a criança começa a mafestar COMP obrigatoriamente preenchido em contextos adequados do PB adulto -QUE-, mesmo antes do sistema morfológico (verbal ou nominal) estar já consolidado.

$\mathrm{Na}$ análise das sentenças complexas produzidas por essas crianças sujeito não foi encontrado nenhum erro, ou desvio, da gramática do adulto, o que contrasta com as observações já clássicas nos estudos de aquisição da linguagem (inclusive do PB) sobre a resistência de erros no sistema morfológico nominal e verbal (das mesmas crianças) até os 3;0 de idade aproximadamente. Tal 
constatação pode ser usada como favorável à hipótese de aquisição proposta dentro do quadro de Princípios e Parâmetros: o que resta à criança aprender é o léxico e a morfologia da língua alvo.

Além das completivas, na mesma época surgem as relativas, também com que, desta vez analisado como pronome relativo (cf. KATO, 1993). ${ }^{5}$

Um outro aspecto que é consensualmente apontado pelos autores que já trataram da questão é que a produção de sentenças complexas tem origem na estrutura dos verbos da sentença matriz, que selecionam complementos sentenciais. São eles em PB: verbos epistêmicos como saber, pensar e achar, o que coincide também com os resultados da pesquisa de DILLINGER et al. (1996), que analisaram os padrões de complementação do adulto no PB falado (dados do NURC) e mostraram, entre outras coisas, com relação à natureza semântica do verbo da sentença matriz, um número maior de epistêmicos, selecionando sentenças finitas.

Os resultados da nossa pesquisa são também perfeitamente compatíveis com os de outros autores que já trataram do desenvolvimento de sentenças complexas com dados de outras línguas, como o inglês, como o antigo texto de LIMBER (1973) que, embora bastante anterior às versões mais modernas da teoria gerativa, faz afirmações compatíveis com estas. Também com relação à faixa etária há perfeita coincidência dos resultados: elas se manifestam em torno dos 2;63;0 de todas as crianças já estudadas.

A mesma ordem de emergência das completivas e das relativas está presente também na pesquisa de BLOOM et al. (1980), os mesmos tipos de verbos das orações matrizes, com a diferença de que as construções completivas do inglês sem o complementador that surgem antes daquelas com o complementador. No caso do PB, isso ocorre nos dados de períodos anteriores a este aqui descrito em contextos com o verbo querer, quando o sujeito da encaixada é idêntico ao da matriz (Ex.s: "Qué pulá”, "Qué pegá!")

Já na análise dos resultados de outras pesquisas realizadas pelo grupo liderado por BLOOM (BLOOM et al., 1984 e 1989), foi constatado 
que as primeiras sentenças complexas a surgir no inglês são as com to + infinitivo. Isto leva o grupo a propor que os verbos que oferecem contextos para o surgimento do to são todos verbos que partilham um elemento de sentido indicando direção ou movimento, concluindo a favor do que chamam de "hipótese semântica", ou seja, as crianças não aprenderiam a partícula to como um marcador sintático sem significação.

Os resultados do estudo de 1989 do mesmo grupo são também idênticos aos aqui mostrados. Retomando a forma that do inglês, os autores afirmam que é usada primeiro como um demonstrativo, não se manifestando como um complementador nas sentenças complexas de seus sujeitos na faixa etária analisada. Sua ausência nas primeiras sentenças complexas das crianças adquirindo o inglês como língua materna poderia ser explicada, como apontado pelos autores, como um reflexo da possibilidade de sua não-realização fonética nas sentenças do adulto, como em: I know $\varnothing$ be is coming tomorrow.

Entre seus principais resultados, os autores mostram que os verbos epistêmicos (como saber, pensar) foram usados pelos seus quatro sujeitos (entre os 2;0 e os 3;0 de idade) com complementos, em oposição a verbos de percepção, como ver, olhar, mostrar. O desenvolvimento da complementação foi considerado por eles notável naquela faixa etária.

Os autores discutem ainda a questão da aquisição de um complementador não se generalizar imediatamente a todos os verbos de sentenças matrizes que o poderiam selecionar, propondo que as crianças o adquirem verbo por verbo. Sua opinião é de que a plurifuncionalidade do that pode inibir sua aquisição como complementador, o que significaria que as crianças não aprendem uma só regra para complementação, mas tal conhecimento depende do conhecimento da subcategorização do verbo da sentença matriz.

Como já apontado, HYAMS (1986) também afirma que se trata de aquisição lexical, já que a escolha do complemento depende das propriedades selecionais do $\mathrm{V}$, o que precisa ser aprendido, assim como os próprios complementadores. 
Retomando nossos resultados, vemos que complementação surge logo aos 2;6, enquanto os casos de adjunção em sentenças complexas surgem em primeiro lugar aos $2 ; 8$, portanto, logo após as relativas e as completivas. Outros tipos de adjunção não surgirão depois dos 3;0, algumas delas bem mais tardiamente, como as condicionais com $s e^{6}$

A expansão da capacidade de produção de mais de duas sentenças deve-se ao acréscimo, além das completivas, das coordenadas e das adjetivas. Posteriormente, dos 3;0 aos 4;0, o desenvolvimento mais notável é o que mostra maior variedade de casos de adjunção: aumento das finais com para, início das temporais com quando e das causais com porque.

Como vimos, comparando os tipos de sentenças complexas entre si, as sentenças encaixadas que são ocorrências de complementação precedem ontogeneticamente os casos de adjunção, como aqueles conhecidos como formando o grupo das subordinadas adverbiais. Qual poderia ser a explicação para tal fato do desenvolvimento?

Julgamos que a resposta está na diferença da natureza estrutural entre complementação e adjunção. Enquanto a primeira é obrigatória, a segunda não o é. O que determina, portanto, o curso da aquisição, não é um fator semântico ou pragmático propriamente dito, como poderiam propor teorias baseadas na hipótese da ancoragem semântica (PINKER, 1987). É, antes disso, o próprio aspecto estrutural, propiciado pela aquisição dos itens lexicais, com suas propriedades formais. Se considerarmos que na GU o módulo $X^{\prime}$ da gramática estabelece que a projeção da estrutura frasal é um primitivo, com relação a CP, a explicação fica óbvia.

Em sentenças simples, a complementação de núcleos lexicais ou funcionais já existe bem antes dos 2;6, desde a fase de duas palavras. No caso dos verbos, os transitivos já vêm com seus complementos (Ex.: "Qué bola", "Dá nenê") o mesmo se dando no caso das preposições (Ex.: "Papatu du papai", "Dá pa nenê."). Significativamente, o que ocorre com as preposições ${ }^{7}$ é que a princípio estão ausentes na FF, mas não seus complementos ("Papatu papai", "Da nenê"). O que 
enfatizamos neste caso é que tais núcleos nunca ocorrem desprovidos de seus complementos, o que criaria verdadeiras sentenças agramaticais (Ex.: *Papatu du $\varnothing "$, * "Da pa $\varnothing "$ ).

Mas, voltando às sentenças complexas com adjunção, o que acontece nos dados? Dentre as diversas possibilidades que as orações adverbiais do $\mathrm{PB}$ apresentam, a primeira a surgir nos dados de ambos os sujeitos foi a final com para. Em trabalho anterior (PERRONI, 1999) analisamos sua estrutura nos dados das crianças aqui mencionadas. Retomemos a relevância do conhecimento precoce do parâmetro de lineariade definido sobre $\mathrm{CP}$ e a direção de adjunção que se correlaciona com ele. Se $\mathrm{C}^{\circ}$ está à esquerda, correlaciona-se com ramificação à direita, ou seja, $C^{\prime}>$ [ $\mathrm{C}^{\circ}$ [IP]], se $\mathrm{C}^{\circ}$ está à direita, correlaciona-se com ramificação à esquerda, ou seja: $\mathrm{C}^{\prime}>$ [[IP] $\left.\mathrm{C}^{\circ}\right]$. Nos estudos mencionados por LUST (1994), as crianças falantes do inglês e do árabe (línguas "head-first") agiram como se as estruturas de ramificação à direita fossem mais acessíveis na produção e na compreensão do que as ramificações à esquerda, quando testadas com sentenças complexas contendo casos de adjunção.

Com relação a nossos resultados, dos três casos de adjunção no nível sentencial, as finais, as causais e as temporais, há total conformidade com o previsto por LUST (1994): sendo o PB uma língua "head first", os complementos de núcleos lexicais vêm sempre à sua direita. No caso das fronteiras entre constituintes sentenciais, a posição à direita é também a privilegiada, para as finais e para as causais, enquanto que para as temporais é a margem direita a privilegiada. Neste ponto, vemos que o que está em questão não é a própria estrutura interna da sentença, mas sua função no todo do qual faz parte. Como já apontado por KATO \& NASCIMENTO (1996) para dados do $\mathrm{PB}$ adulto, os adjuntos temporais têm sua preferência pela margem esquerda prevista por sua função de orientação dos eventos a serem referidos (canonicidade semântica).

Para entendermos a anterioridade das sentenças complexas com para sobre os demais casos de adjunção, retomemos a discussão feita por PERES (inéd.) sobre os diferentes tipos de conexões proposicionais 
explícitas do português do adulto. No tratamento dado às chamadas adverbiais, o autor faz uso de cinco testes sintáticos para identificar semelhanças e diferenças entre elas: ocorrência como complemento de um verbo; aceitação de advérbios de frase; sujeição ao escopo da negação; clivagem e movimento.

Após aplicar tais testes a sentenças do português, o autor conclui que no caso das adverbiais há um grupo específico formado pelas causais, temporais e finais, que são marcadas positivamente em todos os cinco fatores testados. Peres conclui, então, que este grupo é comparável à modificação adverbial propriamente dita, mostrando todas as propriedades que caracterizam a subordinação.

O curioso em nosso estudo é que até os 5;0 de idade dos sujeitos são exatamente estas as adverbiais que se manifestam. Em primeiro lugar, as finais com para + S. não-finita, época do encerramento da coleta dos dados, em seguida as causais e as temporais. As demais não se manifestam até os 5;0 de idade. ${ }^{8}$ Assim, em nossa pesquisa, as finais/causais/temporais consistem realmente um grupo homogêneo, tal como previsto por PERES (inéd.) para o português do adulto, tendo seus testes sido aplicados aos dados infantis, com resultados positivos.

Para melhor entender a manifestação das sentenças complexas com adjunção, o ideal seria analisá-las em conjunto com os casos de coordenação, já que ambas são "transformações generalizadas", nos termos de CHOMSKY (1995): ambas elegem constituintes complexos (sentenças) como unidades de análise e operam sobre elas. $\mathrm{Na}$ verdade, na adjunção chomskyana não há distinção formal entre coordenação e adjunção, em termos de configuração. Mas não nos deteremos nessa tarefa aqui, deixando para um estudo futuro a comparação entre as duas nos dados de crianças adquirindo o PB como língua materna. 


\section{CONCLUSÕES}

As breves resenhas dos estudos gerativistas realizados sobre a aquisição do PB, feitas na seção 2, podem ilustrar os tipos de pesquisas já realizados em nosso país, a natureza dos sistemas sintáticos analisados e a tendência à adesão a versões continuístas da teoria.

Na seção 3 os resultados de nosso estudo sobre complementação e adjunção em sentenças complexas na aquisição do PB mostraram pontos convergentes com os resultados de estudos realizados com dados de línguas diferentes. Resumidamente, são eles: não há constatação da existência de estruturas infantis desviantes da gramática alvo (do adulto) nesse nível; a faixa etária em que COMP é lexicalmente preenchido coincide entre os sujeitos; propriedades selecionais dos verbos das sentenças matrizes dirigem a manifestação da complementação sentencial, o que significa que a aquisição lexical dirige a sintaxe; complementação sentencial precede adjunção; os resultados do estudo da aquisição da adjunção no PB confirmam o já previsto por outros autores sobre a importância do papel do conhecimento precoce do parâmetro da linearidade definido sobre CP e a direção da adjunção a ele relacionada. Todos esses pontos convergentes encontram explicações dentro do modelo gerativista, como tentamos mostrar em nossa análise.

Por outro lado, muito ainda resta por ser analisado e atualmente não é a falta de dados empíricos de crianças em processo de aquisição do PB como língua materna que impedirá os pesquisadores de trabalharem mais na área. A continuidade dessas pesquisas poderá contribuir para ajudar a iluminar não só as questões da aquisição em si, como também aquelas relacionadas à própria teoria que, como é saudável na ciência, continua a evoluir. 


\section{NOTAS}

${ }^{1}$ Doravante PB.

${ }^{2}$ O Português Brasileiro falado por aquelas crianças é o dialeto paulista do interior do Estado.

${ }^{3}$ Entre eles, o do sujeito nulo é sem dúvida o mais explorado de todos.

${ }^{4}$ A razão da escolha desses sujeitos se deveu ao interesse de comparar dados de crianças com estilos de aquisição muito diferentes, para testar seu possível impacto no desenvolvimento sintático. Os resultados de tal comparação foram vistos como fortes argumentos a favor de teorias inatistas da aquisição da linguagem, uma vez que houve total coincidência dos resultados dos dados da primeira criança sujeito com os da segunda, cujo desenvolvimento era a princípio considerado bastante diferente das outras crianças do projeto original da Unicamp.

${ }^{5}$ A hipótese inspirada em ROCHA (1988) sobre o PB adulto, de que a manifestação das primeiras formas de relativas concomitantemente com as completivas das mesmas crianças poderia indicar que o que faria parte da mesma classe sintática do complementador que, ambos introduzindo sentenças finitas, foi descartada.

${ }^{6}$ São os casos de S. matriz + para + S. não finita (PERRONI, 1999).

${ }^{7}$ Conforme pesquisa em andamento.

${ }^{8}$ Com exceção de pouquíssimos casos de condicionais com se nos dados do primeiro sujeito.

\section{REFERÊNCIAS BIBLIOGRÁFICAS}

BLOOM, L.; LAHEY, M.; HOOD, L.; LIFTER, K.; FIESS, K. Complex sentences: acquisition of syntactic connectives and the semantic relations they encode. Journal of Child Language, 7 (2): p. 235-261, Cambridge University Press, Cambridge, 1980.

BLOOM, L.; TACKEFF, J.; LAHEY, M. Learning TO in complement constructions. Journal of Child Language, 11 (2), p. 391-406, Cambridge University Press, Cambridge, 1984.

BLOOM, L.; RISPOLI, M.; GARTNER, B.; HAFITZ, J. Acquisition of complementation. Journal of Child Language, 16, p. 101-120, Cambridge University Press, Cambridge, 1989.

BROWN, R. A first language: the early stages. Harvard Univerisity Press, 1973. 
CERQUEIRA, V. C. A sintaxe dos possessivos no Português Brasileiro. 1996. Tese (Doutorado) - DL, IEL., Unicamp, Campinas.

. Aquisição de possessivos. Cadernos de Estudos Lingüísticos, 36:85-103, DL. IEL, Campinas, Unicamp, 1999.

CHOMSKY, N. Aspects of the theory of syntax. Mass: The MIT Press, 1965.

. Lectures on government and binding. Dordrecht: Foris, 1981.

. Knowledge of language. New York: Praeger, 1986.

. The Minimalist Program. Mass: The MIT Press, 1995.

CORREA, W. R. Orações relativas: o que se fala e o que se aprende no Português do Brasil. 1998. Tese (Doutorado) - DL., IEL, Unicamp, Campinas.

DILlingER, M.; GAlVES, C.; PAGOTTO, E.; CERQUEIRA, V. Padrões de complementação no português falado. Gramática do Português Falado. V. V., Convergências, 275-337. KATO, M. K. (Org.) Ed. da Unicamp/Fapesp, Campinas, 1996.

FONSECA, H.D.C. A aquisição da concordância negativa no Português Brasileiro como segunda língua. 1999. Dissertação (Mestrado) - DL., IEL., Unicamp, Campinas.

GALVES, C. C. Princípios, parâmetros e aquisição da linguagem. Cadernos de Estudos Lingüísticos, 29, p.137-152. DL., IEL., Campinas, Unicamp, 1995.

GONÇAlVES, S. C. A aquisição do Português como segunda lingua: o caso das crianças yuba. 1997. Dissertação (Mestrado) - DL. IEL. Unicamp, Campinas.

GROLLA, E. B. A aquisição da periferia esquerda da sentença em Português Brasileiro. 2000. Dissertação (Mestrado) - DL., IEL., Unicamp, Campinas.

HYAMS, N. Language acquisition and the theory of parameters. Dordrecht: Reidel, 1986.

V2, null arguments and Comp projections. Language acquisition studies in Generative Grammar. 21-55. HOEKSTRA, T.; SCHWARTZ, B. D. (Ed.). John Benjamins, Amsterdam, 1994.

HAUMANN, D. The syntax of subordination. Tübingen: Niemeyer, 1997.

KATO, M. A. Recontando a estória das relativas. Português Brasileiro: uma viagem diacrônica. 223-261. KATO, M.A.; ROBERTS, I. (Ed.). Campinas: Ed. da Unicamp, 1993. 
KATO, M. A. A theory of null objects and the development of a Brazilian child grammar. TRACEY, R.; LATTEY, E. (Ed.) How tolerant is Universal Grammar? Essays on language learnability and language variation. 125-153. Tübingen: Niemeyer Verlag, 1994.

. Raízes não finitas na criança e a construção do sujeito. Cadernos de Estudos Lingüísticos, 29,119-136, DL., IEL, Campinas, Unicamp, 1995a.

. Sintaxe e aquisição na visão de princípios e parâmetros. Letras de Hoje:, 102, 57-74, Porto Alegre, Edipucrs, 1995b.

- Questões atuais da aquisição de L1 na perspectiva da teoria de Princípios e Parâmetros. Cadernos de Estudos Lingüísticos, 36, 11-16, DL., IEL., Campinas, Unicamp, 1999.

KATO, M. A.; RAMOS, J. Trinta anos de Sintaxe Gerativa no Brasil. D.E.L.T.A., v. 15. Número Especial: 105/146. Educ. São Paulo, 1999.

KATO, M. A.; MIOTO, C. Aspectos sintáticos da subordinação de sentenças. (Trabalho inédito).

KATO, M. A.; NASCIMENTO, M. Adjuntos sintáticos e preenchedores discursivos: uma avaliação comparativa. Gramática do Português Falado, v. 5, Convergências: 187-200. KATO, M. A . (Org.). Campinas: Ed. da Unicamp/Fapesp, 1996.

LIMBER, J. The genesis of complex sentences. In: MOORE, T. (Ed.). Cognitive development and the acquisition of language. New York: Academic Press, 1973.

LUST, B. Functional projection of CP and phrase structure parametrization: an argument for the strong continuity hypothesis. Syntactic theory and first language acquisition: cross-linguistic perspectives. v. 1, Heads, projections and learnability. LUST, B.; SUÑER, M..; WHITMAN, J. (Ed.) L.E.A., Hillsdale, N.J., 1994.

MEISEL, J. (Ed.). The acquisition of verb placement: functional categories and V2 phenomena in language development. Dordrecht: Kluwer, 1992.

MEISEL, J. Bilingual first language acquisition. French and German grammatical development. Amsterdam: John Benjamins, 1994.

MEISEL, J.; MÜLLER, N. Finiteness and verb placement in early child grammars: evidence from the simultaneous acquisition of two first languages: French and German. MEISEL, J. (Ed.), 1992, 109-138.

MÜLLER, N. Parameters cannot be reset: evidence from the development of COMP. Bilingual first language acquisition. French and German grammatical development. MEISEL, J. (Ed.), 235-269. Amsterdam: John Benjamins Ed., 1994.

OLIVEIRA, I. O. Algumas considerações sobre a aquisição do sistema flexional no Português Brasileiro. Campinas, Unicamp, 2000. (Trabalho inédito). 
OLIVEIRA, M. O parâmetro do sujeito nulo na aquisição da linguagem. Cadernos de Estudos Lingüísticos, 36, 131/145. Campinas, DL. IEL, Unicamp, 1999.

PALMIERE, D. T. L. O sistema D nas fases iniciais da aquisição da linguagem. Letras de Hoje, 33, n.2, 151-158. EDIPUCRS. Porto Alegre, 1997.

PERES, J.A. Sobre conexões proposicionais em Português. (Trabalho inédito).

PERRONI, M. C. Primeiras sentenças complexas na linguagem da criança. Estudos Lingüisticos XXXVI, Campinas, p. 709-715, 1997.

- PARA na gramática infantil do Português Brasileiro. Letras de Hoje, v. 34, n. 3, p. 83-100, Porto Alegre, EDIPUCRS, 1999a.

. As relativas que são fáceis na aquisição da linguagem. D.E.L.T.A. v.17, n.1, 59-79, Educ-S.P, 2001.

PINKER, S. Language learnability and language development. Harvard U. Press, 1984.

. The bootstrapping problem in language acquisition. Mechanisms of language acquisition. MACWHINNEY, B. (Ed.). L.E.A., Hillsdale, N.J., 1987.

RADFORD, A. Syntactic theory and the acquisition of English syntax. Oxford: Basil Blackwell, 1990.

RIZZI, L. The fine structure of the left periphery. Universidade de Genebra, 1995. (Trabalho inédito).

ROCHA, M.A. F. Complementizadores no Português do Brasil. 1988. Dissertação (Mestrado) - D.L., Iel., Unicamp, Campinas.

SIKANSI, N. As interrogativas Qu- na gramática infantil do Português Brasileiro. Cadernos de Estudos Lingüísticos, 36, 85-103, Campinas, DL., IEL., Unicamp, 1999.

SIMÕES, L. J. Sujeito nulo na aquisição do Português do Brasil: um estudo de caso. Letras de Hoje, v. 32, n. 4:107-123, Porto Alegre, Edipucrs, 1997.

. Sujeito nulo na aquisição do Português Brasileiro. Cadernos de Estudos Lingüísticos, 36, 105/130, Campinas, DL., IEL, Unicamp, 1999.

XAVIER, G. R. A Aquisição do Português Brasileiro por um falante chinês. 1999. Dissertação (Mestrado) - DL. IEL, Unicamp. Campinas. 